\title{
Protection of Alodine Coatings from Thermal Aging by Removable Polymer Coatings
}

R. W. Bradshaw, B. R. Wagstaff and L. L. Whinnery

\section{Prepared by}

Sandia National Laboratories

Albuquerque, New Mexico 87185 and Livermore, California 94550

Sandia is a multiprogram laboratory operated by Sandia Corporation,

a Lockheed Martin Company, for the United States Department of Energy's

National Nuclear Security Administration under Contract DE-AC04-94-AL85000.

Approved for public release; further dissemination unlimited. 
Issued by Sandia National Laboratories, operated for the United States Department of Energy by Sandia Corporation.

NOTICE: This report was prepared as an account of work sponsored by an agency of the United States Government. Neither the United States Government, nor any agency thereof, nor any of their employees, nor any of their contractors, subcontractors, or their employees, make any warranty, express or implied, or assume any legal liability or responsibility for the accuracy, completeness, or usefulness of any information, apparatus, product, or process disclosed, or represent that its use would not infringe privately owned rights. Reference herein to any specific commercial product, process, or service by trade name, trademark, manufacturer, or otherwise, does not necessarily constitute or imply its endorsement, recommendation, or favoring by the United States Government, any agency thereof, or any of their contractors or subcontractors. The views and opinions expressed herein do not necessarily state or reflect those of the United States Government, any agency thereof, or any of their contractors.

Printed in the United States of America. This report has been reproduced directly from the best available copy.

Available to DOE and DOE contractors from

U.S. Department of Energy

Office of Scientific and Technical Information

P.O. Box 62

Oak Ridge, TN 37831

Telephone:

(865) $576-8401$

Facsimile:

(865) $576-5728$

E-Mail:

reports@adonis.osti.gov

Online ordering: hıp://www.doe.gov/bridge

Available to the public from

U.S. Department of Commerce

National Technical Information Service

5285 Port Royal Rd

Springfield, VA 22161

Telephone: $\quad$ (800) 553-6847

Facsimile: (703) 605-6900

E-Mail: $\quad$ orders (antis. fedworld.gov

Online order: $\quad$ http://www.ntis.gov/help/ordermethods.asp?loc=7-4-()\#online 


\title{
Protection of Alodine Coatings from Thermal Aging by Removable Polymer Coatings
}

\author{
R. W. Bradshaw \\ Materials Chemistry Dept. 8778 \\ B. R. Wagstaff \\ W80 System Engineering Dept. 8241 \\ L. L. Whinnery \\ Materials Chemistry Dept. 8778 \\ Sandia National Laboratories \\ Livermore, CA \\ 94551-0969
}

\begin{abstract}
Removable polymer coatings were evaluated as a means to suppress dehydration of Alodine chromate conversion coatings during thermal aging and thereby retain the corrosion protection afforded by Alodine. Two types of polymer coatings were applied to Alodine-treated panels of aluminum alloys 7075-T73 and 6061-T6 that were subsequently aged for 15 to 50 hours at temperatures between $135^{\circ} \mathrm{F}$ to $200^{\circ} \mathrm{F}$. The corrosion resistance of the thermally aged panels was evaluated, after stripping the polymer coatings, by exposure to a standard salt-fog corrosion test and the extent of pitting of the polymercoated and untreated panels compared. Removable polymer coatings mitigated the loss of corrosion resistance due to thermal aging experienced by the untreated alloys. An epoxide coating was more effective than a fluorosilicone coating as a dehydration barrier.
\end{abstract}




\section{Acknowledgements}

The authors gratefully acknowledge the important contributions to this study made by Chris Binns, formerly 8762, for masking and thermal aging of panels. John Hachman and Dorrance McLean, both 8753, performed the Alodine processing and Bill Anderson, 8773, assisted with panel preparation and salt fog chamber operation.

Sandia National Laboratories is a multiprogram laboratory operated by Sandia Corporation, a Lockheed Martin company, for the United States Department of Energy's National Nuclear Security Administration under contract DE-AC04-94AL85000. 


\section{Contents}

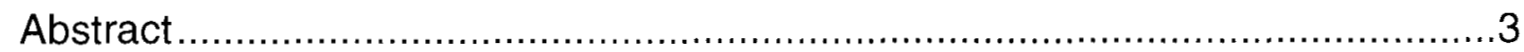

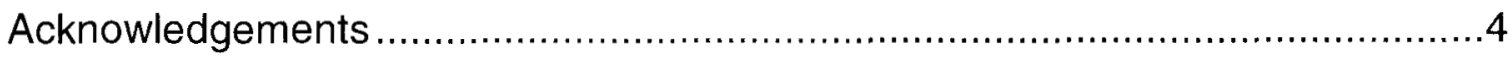

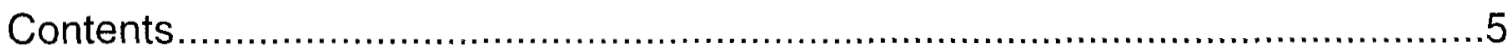

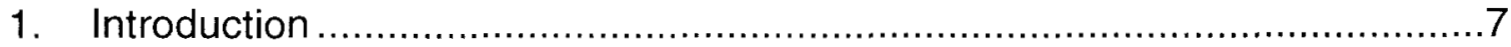

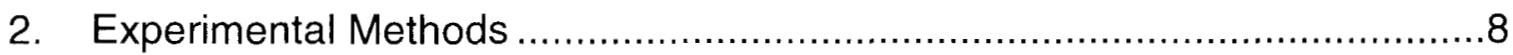

2.1 Aluminum Alloy Material and Alodine Coating ..................................

2.2 Polymer Barrier Materials .......................................................

2.3 Thermal Aging Environments ............................................... 10

2.4 Corrosion Testing ............................................................ 10

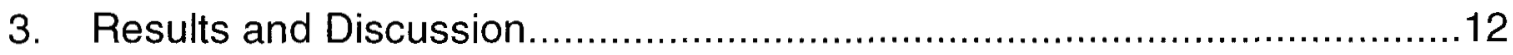

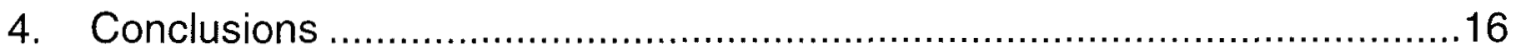

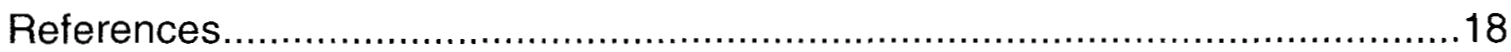

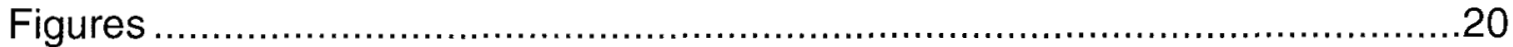

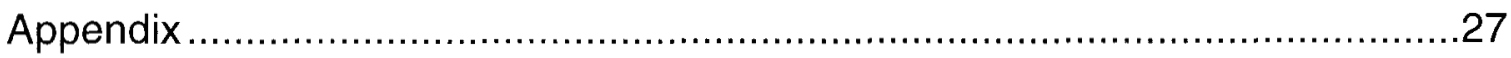

Pitting Data for Aluminum Alloys 7075-T73 and 6061-T6 .......................27 


\section{List of Figures}

Figure 1. Photograph of corrosion test panel with masking materials applied. Upper band, Miccropeel; lower band, Silastic-J. The center band was not masked. The dimensions of the panel are 3 in. by 6 in.

Figure 2. Photograph of Alodine corrosion test panel racks loaded in the salt fog chamber.

Figure 3. Photographs of selected Al-7075-T73 corrosion test panels after 72 hours in salt fog; panel aged 50 hours at $135^{\circ} \mathrm{F}$ (upper) and 50 hours at $155^{\circ} \mathrm{F}$ (lower). Each panel is oriented so that the upper band was masked with Miccropeel, the center was not masked and the lower was masked with Silastic-J.

Figure 4. Photographs of selected Al-6061-T6 corrosion test panels after 72 hours in salt fog; panel aged 34 hours at $165^{\circ} \mathrm{F}$ (upper) and 15 hours at $180^{\circ} \mathrm{F}$ (lower). Each panel is oriented so that the upper band was masked with Miccropeel, the center was not masked and the lower was masked with Silastic-J.

Figure 5. The effect of removable masking materials on thermal aging of Alodine Grade 1 coatings on Al-7075-T73 corrosion test panels after 72 hours in a salt fog chamber. Shorter bars indicate less pitting susceptibility....

Figure 6. The effect of removable masking materials on thermal aging of Alodine Grade 1 coatings on Al-6061-T6 corrosion test panels after 72 hours in a salt fog chamber. Shorter bars indicate less pitting susceptibility

\section{List of Tables}

Table 1. Elemental composition (wt.\%) of aluminum alloys used in these experiments. Balance is aluminum.

Table 2. Thermal aging conditions used for polymer-coated aluminum alloy corrosion test panels.

Table 3. Comparative values of pitting susceptibility of Alodine-coated aluminum alloys 7075-T73 and 6061-T6 in a salt fog environment. The effect of coatings are shown corresponding to various thermal aging treatments. Higher values indicate greater corrosion.

Table 4. Visually determined values of pitting susceptibility of Alodine-coated Aluminum alloys 7075-T73 and 6061-T6 after 72 hours in a salt fog chamber. Data for dehydration barrier coatings are compared following various thermal aging treatments. 


\section{Protection of Alodine Coatings from Thermal Aging by Removable Polymer Coatings}

\section{Introduction}

Aluminum alloys are widely used to fabricate structural components and electronics housings for nuclear weapon systems and are ordinarily protected from corrosion by Alodine chromate conversion coatings. These components may also require electrical conductivity between the aluminum alloy surfaces and interfacing components. Alodine coatings prevent aluminum from forming an oxide layer which is inherently nonconductive and establish conductive paths via intrinsic micro-cracks without compromising corrosion resistance. However, these parts may be exposed to thermal environments in the stockpile and during component fabrication or rework that exceed those specified in the chromate coating material specification.[1] Thermal aging of the Alodine coating may degrade its ability to resist corrosion.

An Alodine conversion coating is a hydrated chromate film. The water molecules incorporated into the film are necessary for the chromate conversion coating to function effectively. If the conversion coating is exposed to temperatures higher than ambient, the film loses water molecules.[2] A dehydrated chromate film may not provide sufficient corrosion protection nor can the process of dehydration be reversed to restore the original composition.[3] Dehydration kinetics of chromate coatings are not known quantitatively, thus it is difficult to identify an exact temperature and time envelope that will cause excessive dehydration. In addition, a chromate film will not provide clear visual evidence of its integrity. Consequently, the ability of a chromate coating to mitigate corrosion must be determined by exposing the film to a corrosive environment. This type of test provides a comparison of the severity of corrosion between a thermally aged chromate coating and an as-prepared, unaged chromate coating that will help identify maximum temperature and exposure time boundaries for component reprocessing.

One approach to preventing dehydration of Alodine films during re-processing of aluminum alloy components at elevated temperature is to temporarily mask the surfaces with a barrier to moisture evolution. We evaluated two types of easily removable polymeric coatings as dehydration barriers for treating Alodine-coated corrosion test panels. After thermal aging at various temperatures and time intervals, the polymer films were stripped and the panels subjected to a salt fog corrosion test. The salt fog environment is very aggressive compared to the anticipated service conditions of these components and is not intended as an accelerated test to predict service lifetimes. Rather, the corrosion resistance of unprotected Alodine surfaces was compared to polymer-coated Alodine surfaces to determine the effectiveness of the removable dehydration barrier technique. 
Intentionally Left Blank 


\section{Experimental Methods}

\subsection{Aluminum Alloy Material and Alodine Coating}

The aluminum alloys of interest are Al-7075-T7351 and Al-6061-T6 which are used to construct weapon components. The elemental compositions of these alloys are given in Table 1. Al-7075 is a relatively highly-alloyed material that provides high strength. Corrosion test panels were obtained from Q-Panel Co., Cleveland, OH with dimensions of 3 in. $x 6$ in. $x 0.032$ in thick with a single 0.25 in. dia. mounting hole. Each panel was scribed with a stylus to designate the alloy type and panel number. Test panels of 7075 were purchased in the $\mathrm{T} 6$ condition and were subsequently heat-treated to convert them to the T73 condition. Heat treatment was performed by Pacific Heat Treating Co., Sunnyvale, CA. Although the specification for the component requires that 7075 be in the T7351 condition, it was not feasible to duplicate the mechanical processing necessary for this condition given the large number of test panels. The mechanical processing is for stress relief, so we assume that neglecting this step would have a negligible effect on the corrosion behavior of Alodine-coated 7075-T73 material. Alodine Grade 1 chromate conversion coatings were applied to Al-7075-T73 and Al-6061-T6 panels according to specification 9904151.[4] Due to the large number of panels in the test matrix, the panels were processed in several batches for each alloy.

Table 1. Elemental composition (wt.\%) of aluminum alloys used in these experiments. Balance is aluminum.

\begin{tabular}{|c|l|l|l|l|c|}
\hline Alloy & $\mathrm{Mg}$ & $\mathrm{Cu}$ & $\mathrm{Zn}$ & $\mathrm{Cr}$ & Other \\
\hline 7075 & $2.1-2.9$ & $1.2-2.0$ & $5.1-6.1$ & $0.18-0.28$ & $0.40 \mathrm{Si}$ \\
\hline 6061 & $0.8-1.2$ & $0.15-0.40$ & -- & $0.04-0.35$ & $0.4-0.8 \mathrm{Si}$ \\
\hline
\end{tabular}

\subsection{Polymer Barrier Materials}

Corrosion test panels were prepared with areas masked by either of two polymeric coatings and an untreated area to facilitate comparison of corrosion resistance. Miccropeel (Tolber Chemical Co., Hope, AR) and Silastic-J (Dow Corning, Midland, MI) were used as the dehydration barrier coatings. Miccropeel is an epoxide suspension in acetone that contains approximately $3 \mathrm{wt} . \%$ chromia and is applied as a paint. Four coats of this material were brushed onto the panels and allowed to dry between each application. 3M electroplating masking tape was used to provide a boundary for the brush application. Silastic-J is a fluorosilicone coating that was applied to the substrate by dipping. Figure 1 shows a typical test panel with the removable polymer coatings applied. After thermal aging, the polymer layers were removed, Miccropeel by dissolution in acetone and Silastic-J by 
simply peeling the intact film from the panel. Both coatings were easily removed except that a longer soaking period was necessary to completely strip Miccropeel after aging at the highest temperature $\left(200^{\circ} \mathrm{F}\right)$. Visual inspection did not reveal any effect on the underlying Alodine films after processing.

\subsection{Thermal Aging Environments}

The thermal aging conditions were chosen to provide a broad range of temperature and time encompassing the anticipated re-processing conditions of the components of interest. Thermal aging was accomplished by heating the masked panels in laboratory ovens, under air, to temperatures from $135^{\circ} \mathrm{F}$ to $200^{\circ} \mathrm{F}$ for periods of time between 15 hours and 50 hours. The temperature-time matrix is shown in Table 2. Several coupons of each Alodinecoated alloy were not aged after the polymer coating and removal process in order to provide a baseline for comparison. An additional few panels were tested in the as-Alodined condition, without masking or aging, to provide controls for the corrosion testing. The baseline panels were stored in the ambient laboratory environment for several days after Alodine coating prior to testing, as were the thermally-aged panels.

Table 2. Thermal aging conditions used for polymer-coated aluminum alloy corrosion test panels.

\begin{tabular}{|c|c|c|c|c|c|c|}
\hline $\begin{array}{c}\text { Time } \\
\text { (hours) }\end{array}$ & \multicolumn{7}{|c|}{$\begin{array}{c}\text { Temperature } \\
\left({ }^{\circ} \mathrm{F}\right)\end{array}$} \\
\hline & Ambient & 135 & 155 & 165 & 180 & 200 \\
\hline (days) & $\mathrm{X}$ & & & & & \\
\hline 15 & & & & $\mathrm{X}$ & $\mathrm{X}$ & $\mathrm{X}$ \\
\hline 25 & & & $\mathrm{X}$ & $\mathrm{X}$ & $\mathrm{X}$ & $\mathrm{X}$ \\
\hline 34 & & $\mathrm{X}$ & $\mathrm{X}$ & $\mathrm{X}$ & $\mathrm{X}$ & \\
\hline 50 & & $\mathrm{X}$ & $\mathrm{X}$ & $\mathrm{X}$ & & \\
\hline
\end{tabular}

\subsection{Corrosion Testing}

The masked regions of the coupons were removed prior to corrosion testing. The coupons were not further cleaned or exposed to fingerprints or other oils that may contaminate the surfaces prior to corrosion testing. The corrosion testing conditions were as specified for salt fog corrosion tests according to ASTM B117-03 [5], except that the exposure period was shortened to 72 hours instead of 168 hours. The panels were suspended from acrylic or PVC rods in a Q-Fog Model SF/MP450 Salt Fog Chamber (Q-Panel Co., Cleveland, OH). The panels were hung by waxed fabric strings to avoid galvanic effects with metallic hangers. Figure 2 shows the arrangement of racked corrosion test panels in the salt fog chamber prior to testing. The salt fog chamber was run for three periods of 24 hours each and panels were rinsed and visually inspected after each interval. Panels of 7075-T73 and 
6061-T6 that were not coated with Alodine were also included in each testing sequence to confirm the corrosiveness of the salt fog environment. As expected, these panels were severely corroded after only 24 hours of exposure. After a total of 72 hours of salt fog exposure, the panels were rinsed with warm water, dried, visually inspected and individually photographed with identification labels. Two campaigns of three days each were required to complete the test matrix, which included replicate panels exposed in separate 3-day runs.

Pitting is the primary mechanism of corrosion of aluminum alloys in an aerated saline environment, so the corrosion behavior of the panels was evaluated after salt fog testing based on ASTM G46-94.[6] This specification describes criteria for classifying the extent of pitting by visual inspection (areal pit density, pit diameter) and metallographic analysis (pit depth). Because the purpose of this investigation was simply to determine the efficacy of dehydration barriers on Alodine coatings, areal pit density was used as the metric of corrosion. G46-94 assigns a numerical value between 1 and 5 based on the number of pits per unit area such that increasing corrosion corresponds to larger ranking values and the density of pits increases exponentially with the ranking value rather than linearly. The corroded panels were inspected visually using a low-magnification laboratory viewer under oblique illumination and the pitting susceptibility ranking assigned based on comparison to Figure 2 in G46-94. If no pits were observed, a ranking value of zero was assigned. A ranking of zero is a deviation from the standard but provided more differentiation between panel responses in these short-term tests. The assigned rankings were cross-checked by reexamining randomly selected panels and comparing the second evaluation with the initial rankings. This comparison typically agreed quite well. 
Intentionally Left Blank 


\section{Results and Discussion}

Although every panel was photographed after 72 hours of salt fog testing, only a small number can be shown here. Those discussed below represent the general corrosion behavior and the effects of masking materials and thermal aging. Photographs of selected panels of Al-7075-T73 after 72 hours of exposure in the salt fog chamber are shown in Fig. 3. The orientation of the panels is such that the band that was masked by Miccropeel comprises the top one-third of the photo, the unmasked Alodine band is at the center and the lower one-third was the section masked by Silastic-J. The upper panel in Figure 3 was thermally-aged for 50 hours at $135^{\circ} \mathrm{F}$ and distinct differences in the extent of pitting among the three bands are evident. This panel shows considerable pitting in the center band but little in the upper and lower bands, which were masked. The pitting rankings determined for these areas were 1-4-1, respectively. The 7075-T3 panel in the lower photo in Figure 3 was thermally-aged for 50 hours at $155^{\circ} \mathrm{F}$ and experienced more pitting than the panel aged at the lower temperature. The upper band (Miccropeel coating) is less pitted than the unprotected center band, which is more pitted than the lower band (Silastic-J coating). The pitting rankings assigned to these areas were 1-4-3, respectively.

Figure 4 displays photographs of two panels of Al-6061-T6 after 72 hours of exposure in the salt fog chamber. The arrangement of the photos is the same as Fig. 3. The upper panel in Figure 4 was thermally-aged for 34 hours at $165^{\circ} \mathrm{F}$ and distinct differences in the extent of pitting among the three bands are evident. This panel shows considerable pitting in the center band but virtually none in the upper band and an intermediate amount in the lower band. The pitting rankings of the corrosion assigned to these areas were 1-3-2, respectively. The panel in the lower photo in Figure 4 was thermally-aged for 15 hours at $180^{\circ} \mathrm{F}$ and experienced similar pitting to the panel aged at a lower temperature. The upper band (Miccropeel coating) is less pitted than the unprotected center band, which is in turn, more pitted than the lower band (Silastic-J coating). The rankings assigned to these areas were $1-3-2$, respectively.

The pitting susceptibility data for all panels after salt fog testing are plotted in bar charts in Figure 5 (7075-T73) and Figure 6 (6061-T6). These charts show the pitting ranking on the $\mathrm{Y}$-axis and the temperature-time conditions of thermal aging on the $\mathrm{X}$-axis. The pitting rankings of each panel area from duplicate salt fog tests were summed, rather than averaged, to retain simple integer values for comparing corrosion behavior. Thus, the aggregate ranking in the bar charts ranges from 0 to 10 . At each temperature-time parameter, the bars are clustered for comparison of the effect of the polymer coatings. The center bar represents corrosion of the unprotected Alodine surface, while the bars to the left and right represent corrosion of the areas protected by Miccropeel (red bars) and Silastic-J (green bars), respectively. The category, $70^{\circ} \mathrm{F}$, represents Alodine-coated panels that were masked and stripped but not thermally-aged and panels that were neither masked nor aged. No significant difference was observed between these two types of treatments with regard to corrosion resistance. The numerical data used to construct the charts are collected in the Appendix. 
Several aspects of the corrosion behavior of these alloys are readily apparent from the two bar charts. Consider first the effect of thermal aging on corrosion of the baseline Alodinecoated alloys. Increasing the aging time at a given temperature generally increased the extent of pitting of Al-7075-T73 and Al-6061-T6. Such behavior is expected based on reports in the corrosion literature regarding increasing dehydration of Alodine coatings as temperature and time are increased.[2,3] Unfortunately, we have not located any publications that quantitatively describe the relation between aging time and temperature and corrosion. Unaged Al-7075-T73 panels (those stored at ambient temperature) did not experience pitting except for one instance, while unaged 6061-T6 displayed negligible pitting in that two areas were rated ' 1 ' on the scale of pitting ranking. The effect of aging on pitting is evident for 7075-T73, see Figure 5, where the aggregate pitting ranking values typically equal or exceed six upon aging for 25 hours or more. A similar observation with regard to 6061-T6 may be made from the data in Figure 6.

Comparing the pitting susceptibility of the two alloys according to the application of dehydration barrier coatings, shown in Figures 5 and 6, leads to the conclusion that corrosion was mitigated by the polymer coatings. Al-7075-T73 panels masked with either Miccropeel or Silastic-J displayed less pitting than bare Alodine for all thermal aging conditions except 25 hours at $200^{\circ} \mathrm{F}$. At that condition, Silastic-J behaved equivalently to bare Alodine, while Miccropeel reduced pitting. Al-6061-T6 panels showed essentially the same comparative pitting behavior. The barrier coatings reduced pitting of aged 6061-T6 to some degree, compared to bare Alodine, with the sole exception being the panels aged at $200^{\circ} \mathrm{F}$ for 25 hours. At that condition, the Silastic-J-coated area was marginally more pitted than bare Alodine. This relatively greater corrosion may be due to the stochastic nature of pitting and the inherent variability of the salt fog chamber environment.

A few exceptions to the general behavior described above can be found in Figures 5 and 6 . An obvious exception is the $6061-\mathrm{T} 6$ panels that were aged at $135^{\circ} \mathrm{F}$ for 50 hours. The three bands on this panel displayed less pitting than a companion panel aged for 35 hours. We note that the $135^{\circ} \mathrm{F}-50$ hour panel adheres to the trend of corrosion behavior of 6061 T6 panels aged for 50 hours much more closely than the panel aged at $135^{\circ} \mathrm{F}-35$ hours does within its corresponding group. Given the limitations to this study, it is not possible to determine precise causes for the exceptional behavior observed. We attribute the variations to random differences in the preparation of the Alodine coatings, as discussed in the Experimental Methods section. Focusing on the main trends in corrosion behavior and effects of the processing parameters as they depend on the dehydration barrier coatings is the primary purpose of this work.

Pitting susceptibility was evaluated by quantitative analysis of trends in the data and the results appear in Table 3 . The table gives comparative pitting values according to the aging temperatures of the alloy panels. The figures-of-merit for pitting susceptibility in Table 3 were obtained by adding the pitting rankings for each area of each alloy aged at the indicated temperature. Data for all of the aging times at any given temperature were 
summed and the number of panels to which data correspond at each aging temperature is noted. The figures-of-merit are intended for comparison of the effects of coatings, not to deduce detailed aspects of corrosion behavior or mechanisms of aging. The complete set of data for individual panels is collected in the Appendix.

According to the convention of ASTM G46-94, smaller ranking values indicate less corrosion and thus better performance. Table 3 makes quite clear that Miccropeel preserves pitting protection at all thermal aging treatments compared to uncoated Alodine. At every temperature, the figure-of-merit for Miccropeel is less than that for bare Alodine. Silastic-J coatings maintained substantially better corrosion resistance than uncoated Alodine except at the highest aging temperature, $200^{\circ} \mathrm{F}$, where the ranking values are equal. However, Silastic-J was somewhat less effective as a dehydration barrier coating than Miccropeel.

Table 3. Comparative values of pitting susceptibility of Alodine-coated aluminum alloys 7075T73 and 6061-T6 in a salt fog environment. The effect of coatings are shown corresponding to various thermal aging treatments. Higher values indicate greater corrosion.

\begin{tabular}{|c|c|c|c|c|c|c|}
\hline Aging Temp. & $135^{\circ} \mathrm{F}$ & $155^{\circ} \mathrm{F}$ & $165^{\circ} \mathrm{F}$ & $180^{\circ} \mathrm{F}$ & $200^{\circ} \mathrm{F}$ & $\begin{array}{c}\text { No } \\
\text { Aging }\end{array}$ \\
\hline $\mathbf{7 0 7 5 - T 7 3}$ & & & & & & \\
\hline Miccropeel & 2 & 6 & 1 & 6 & 6 & 0 \\
\hline No mask & 14 & 16 & 13 & 22 & 11 & 0 \\
\hline Silastic-J & 8 & 10 & 7 & 13 & 11 & 0 \\
\hline \# panels & 4 & 6 & 8 & 6 & 4 & 2 \\
\hline 6061-T6 & & & & & & \\
\hline Miccropeel & 2 & 10 & 12 & 8 & 5 & 0 \\
\hline No mask & 7 & 18 & 19 & 17 & 10 & 1 \\
\hline Silastic-J & 5 & 13 & 13 & 9 & 10 & 1 \\
\hline \# panels & 4 & 6 & 8 & 6 & 4 & 2 \\
\hline
\end{tabular}


Intentionally Left Blank 


\section{Conclusions}

The corrosion resistance of Alodine-coated aluminum alloys Al-7075-T73 and Al-6061-T6 that were protected by removable polymer coatings during thermal aging treatments was superior to unprotected Alodine films as determined by a salt fog corrosion test. Removable polymer coatings presumably retarded dehydration of the Alodine chromate conversion coatings during thermal aging conditions representative of the temperature-time cycles expected for component reprocessing. Such dehydration is a recognized cause of diminished corrosion protection provided by chromate-based conversion coatings.

An epoxide coating (Miccropeel) was more effective than a fluorosilicone coating (Silastic-J) in protecting the Alodine film, although the latter enhanced corrosion resistance significantly compared to the absence of a dehydration barrier coating. The polymer coatings evaluated in this study are not necessarily the optimal choices for this application, but were readily available and demonstrated that the concept of temporary dehydration barriers is feasible. The candidate polymer coatings were simple to apply and to remove after thermal processing. 
Intentionally Left Blank 


\section{References}

1. MIL-C-5541E, Chemical Conversion Coatings on Aluminum and Aluminum Alloys, Military Specifications, Nov. 30, 1990.

2. V. Laget, C. S. Jeffcoate, H. S. Issacs and R. G. Buchheit, J. Electrochem. Soc., $\underline{150}$ (9), B425 (2003).

3. W. Zhang and R. G. Buchheit, Corrosion (NACE), $\underline{59}$ (4), 356 (2003).

4. "Coating, Chromate on Aluminum", Specification 9904151, Issue AF, Sandia National Laboratories, 9/14/1992.

5. "Standard Practice for Operating Salt Spray (Fog) Apparatus", ASTM B117-03, ASTM International, Philadelphia, PA (2003).

6. "Standard Guide for Examination and Evaluation of Pitting Corrosion", ASTM G4694 (reapproved 2005), ASTM International, Philadelphia, PA (2005). 
Intentionally Left Blank 


\section{Figures}

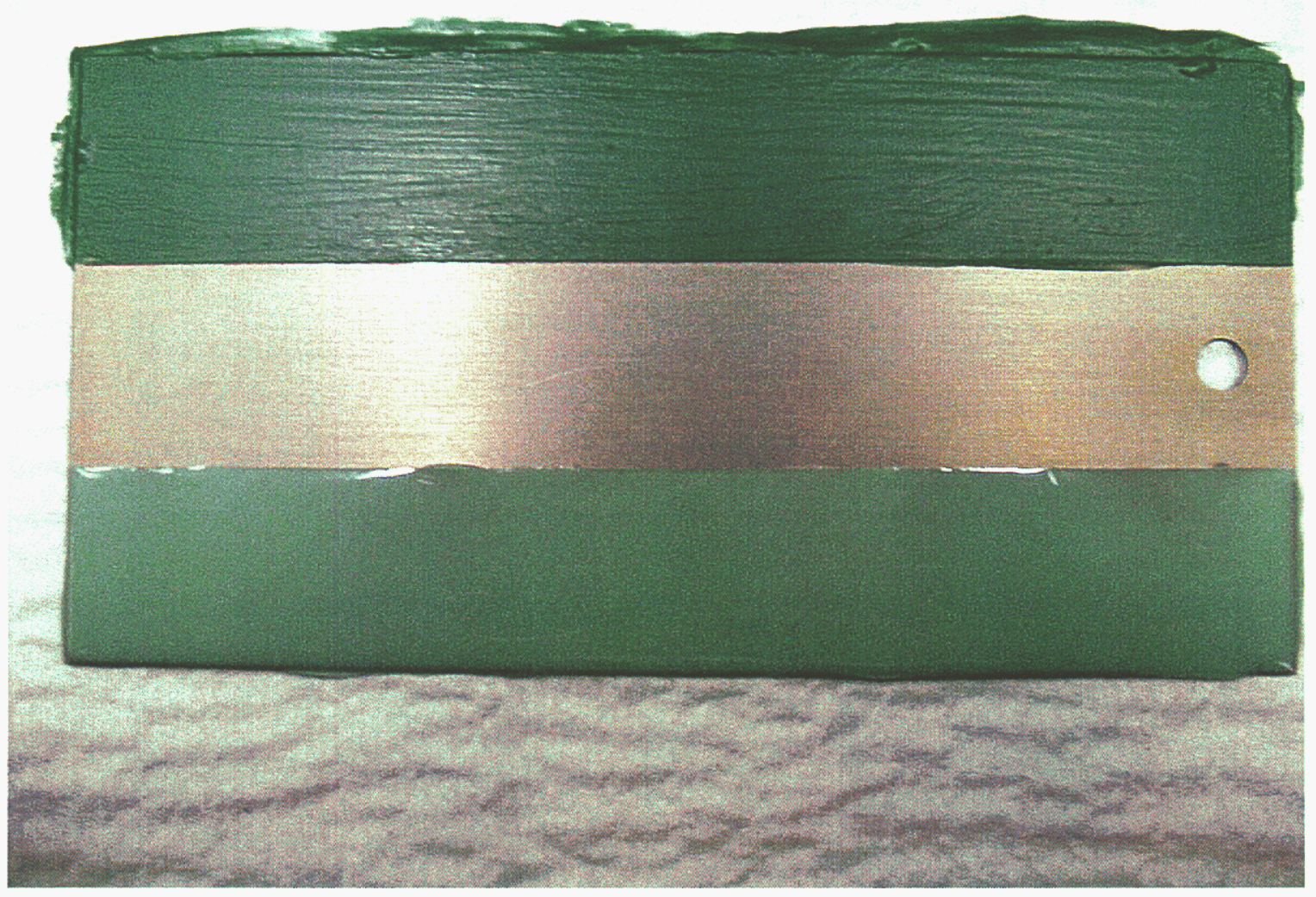

Figure 1. Photograph of corrosion test panel with masking materials applied. Upper band, Miccropeel; lower band, Silastic-J. The center band was not masked. The dimensions of the panel are 3 in. by 6 in. 


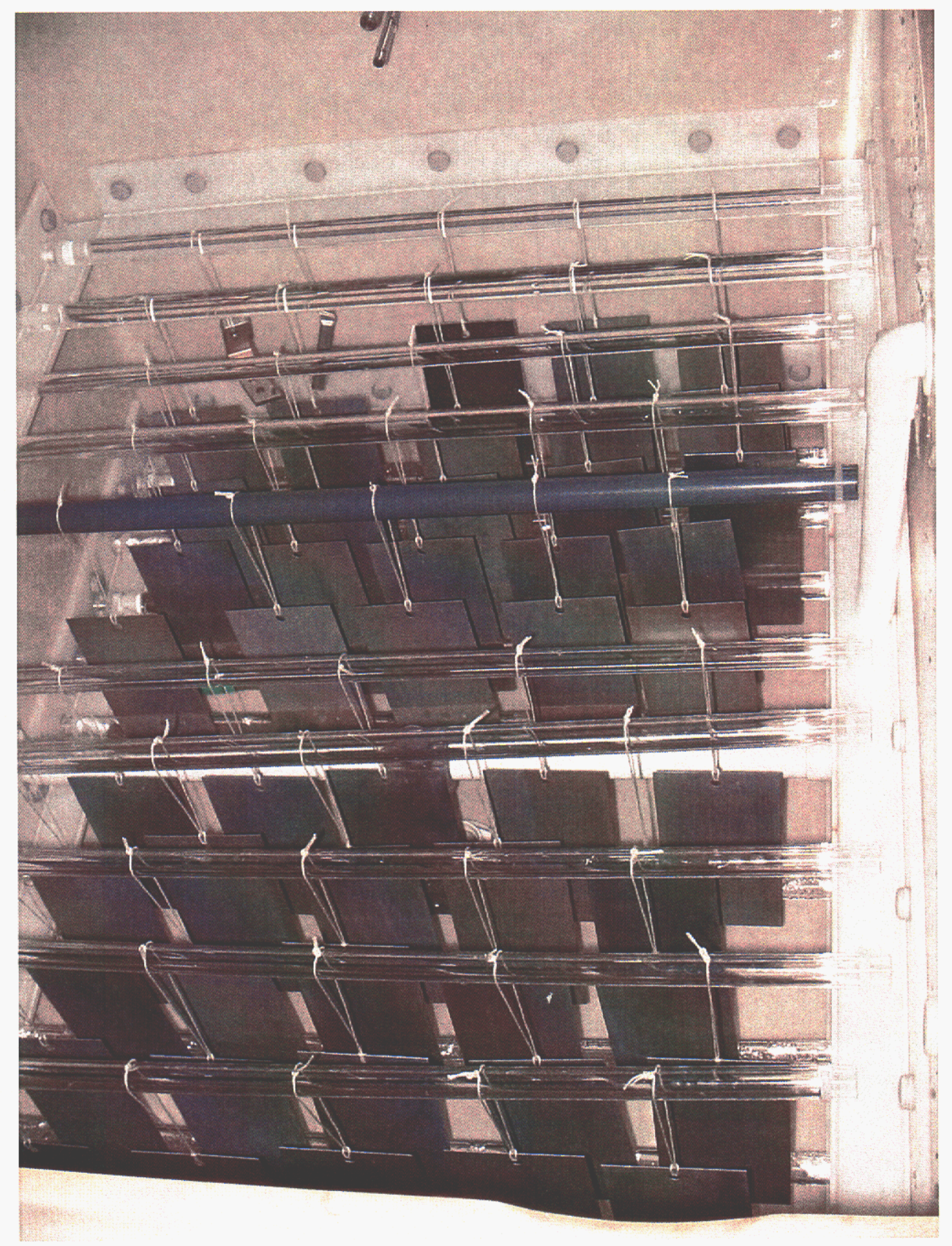

Figure 2. Photograph of Alodine corrosion test panel racks loaded in the salt fog chamber. 
72 hrs

766

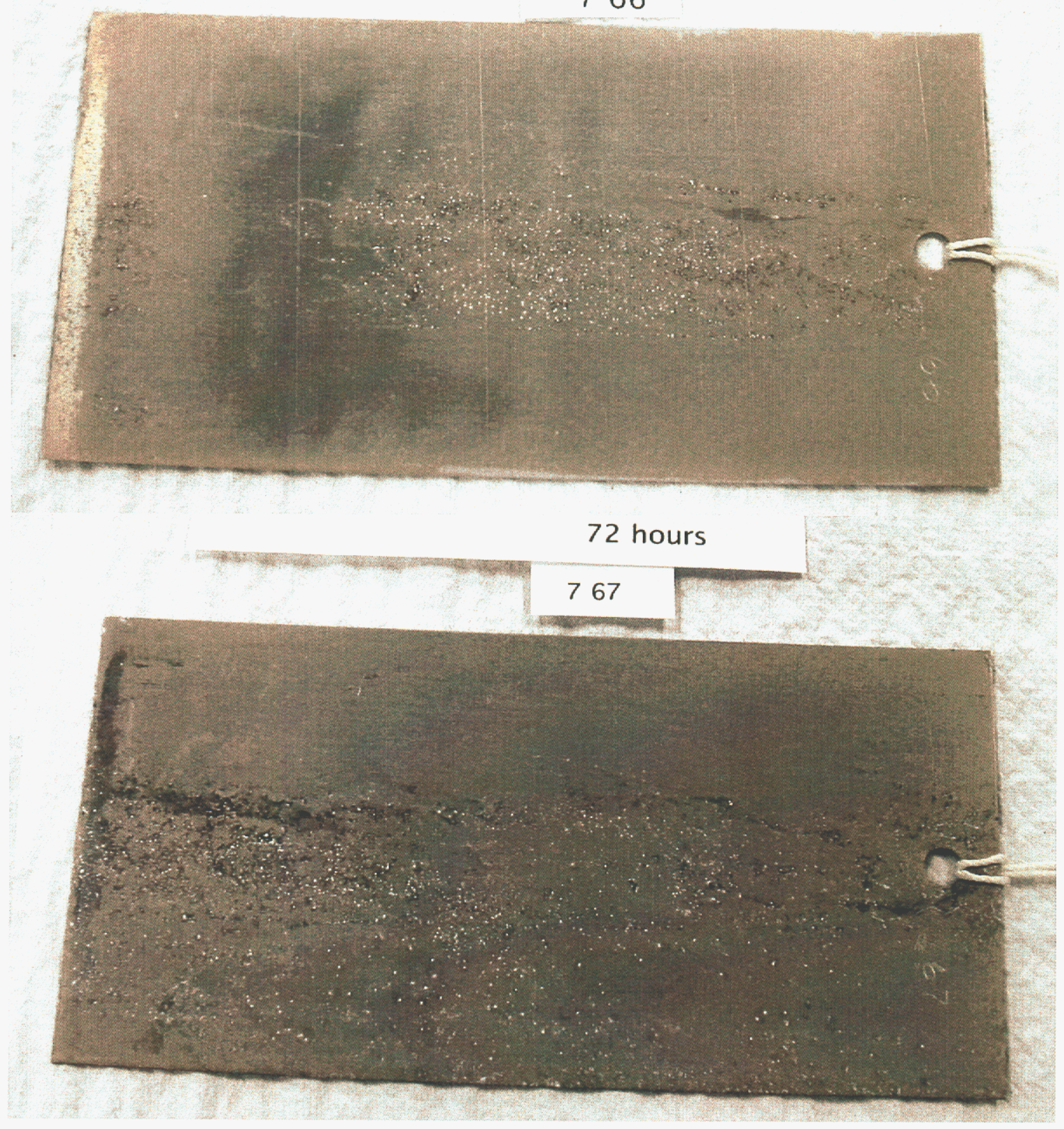

Figure 3. Photographs of selected Al-7075-T73 corrosion test panels after 72 hours in salt fog; panel aged 50 hours at $135^{\circ} \mathrm{F}$ (upper) and 50 hours at $155^{\circ} \mathrm{F}$ (lower). Each panel is oriented so that the upper band was masked with Miccropeel, the center was not masked and the lower was masked with Silastic-J. 


\section{2 hours}
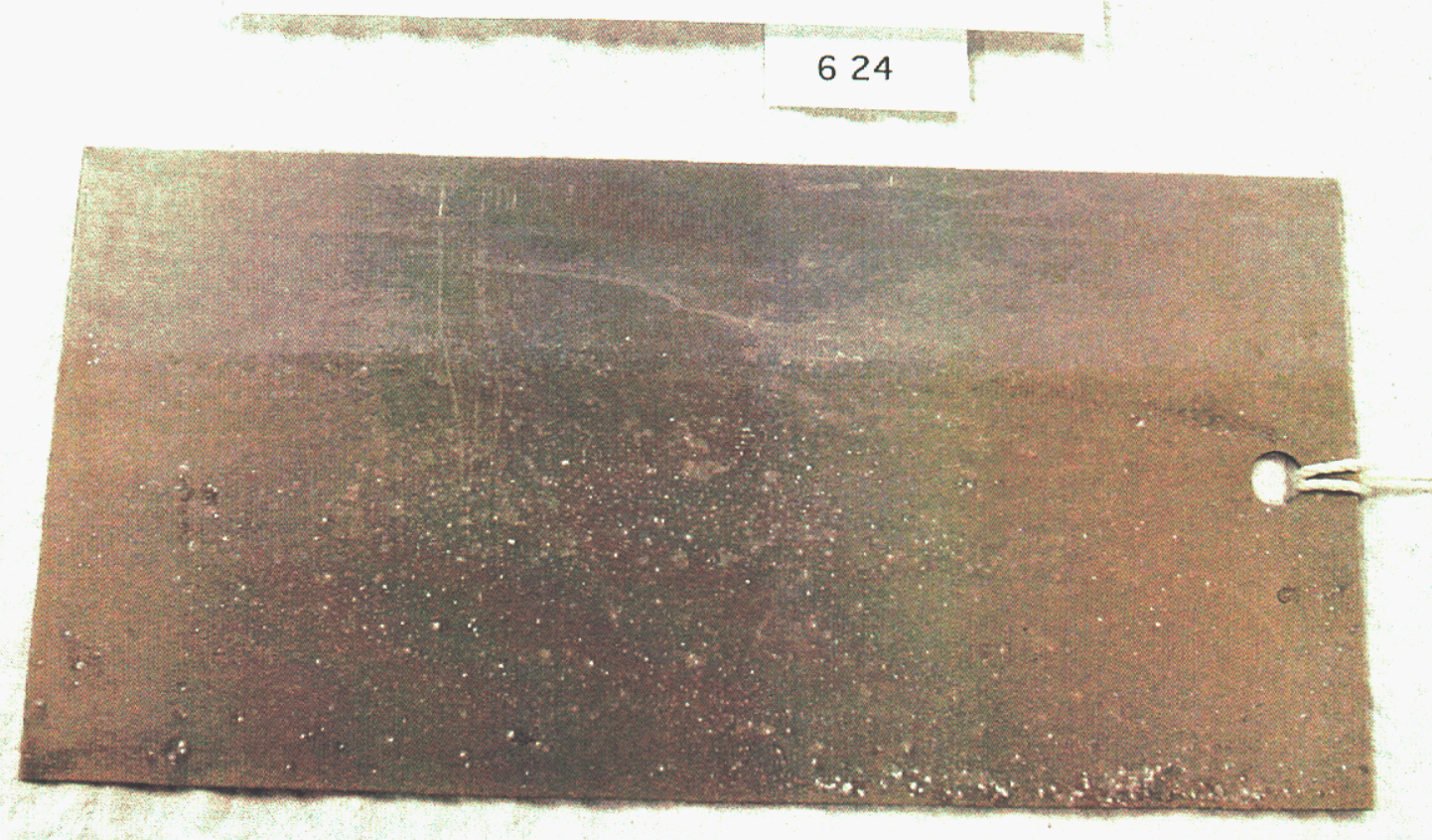

\section{2 hours}

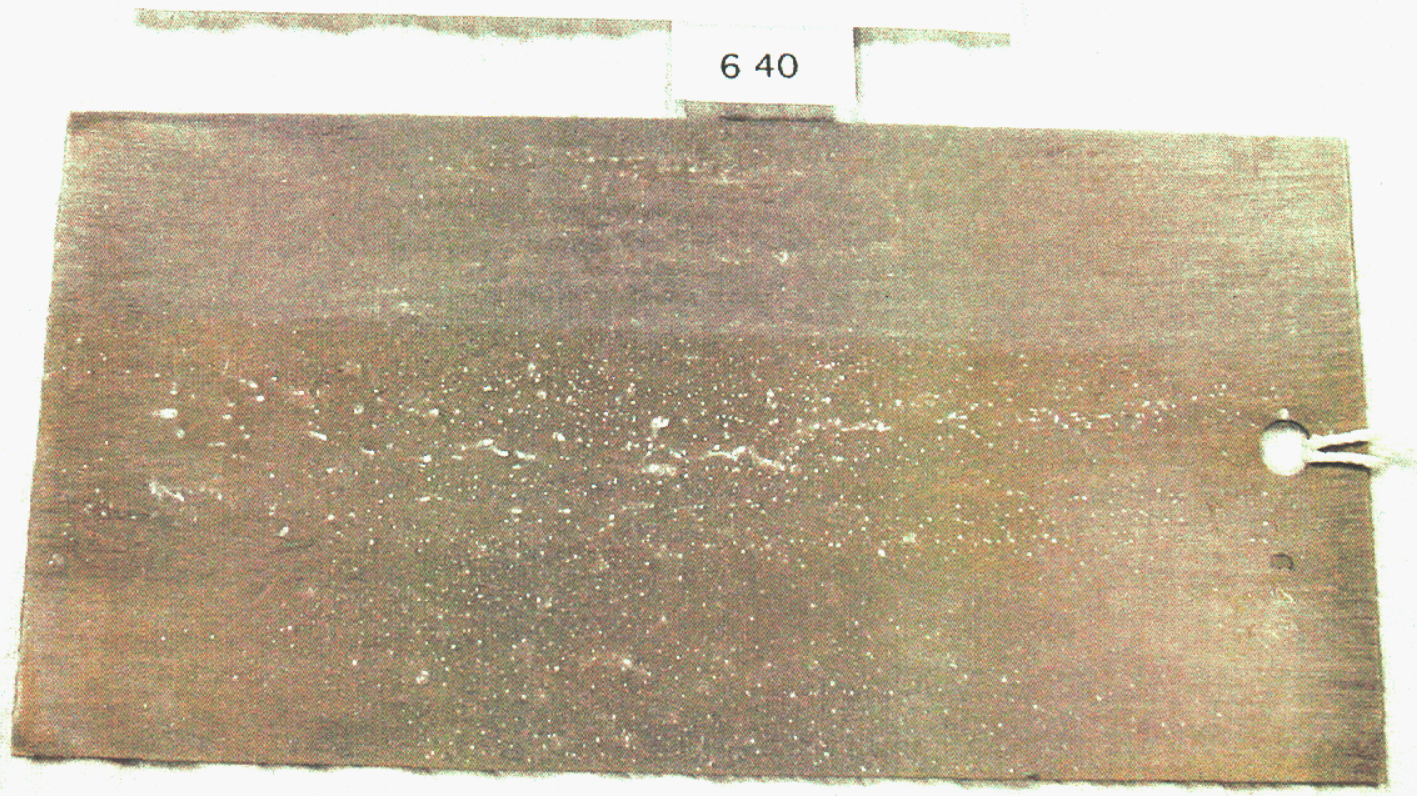

Figure 4. Photographs of selected Al-6061-T6 corrosion test panels after 72 hours in salt fog; panel aged 34 hours at $165^{\circ} \mathrm{F}$ (upper) and 15 hours at $180^{\circ} \mathrm{F}$ (lower). Each panel is oriented so that the upper band was masked with Miccropeel, the center was not masked and the lower was masked with Silastic-J. 


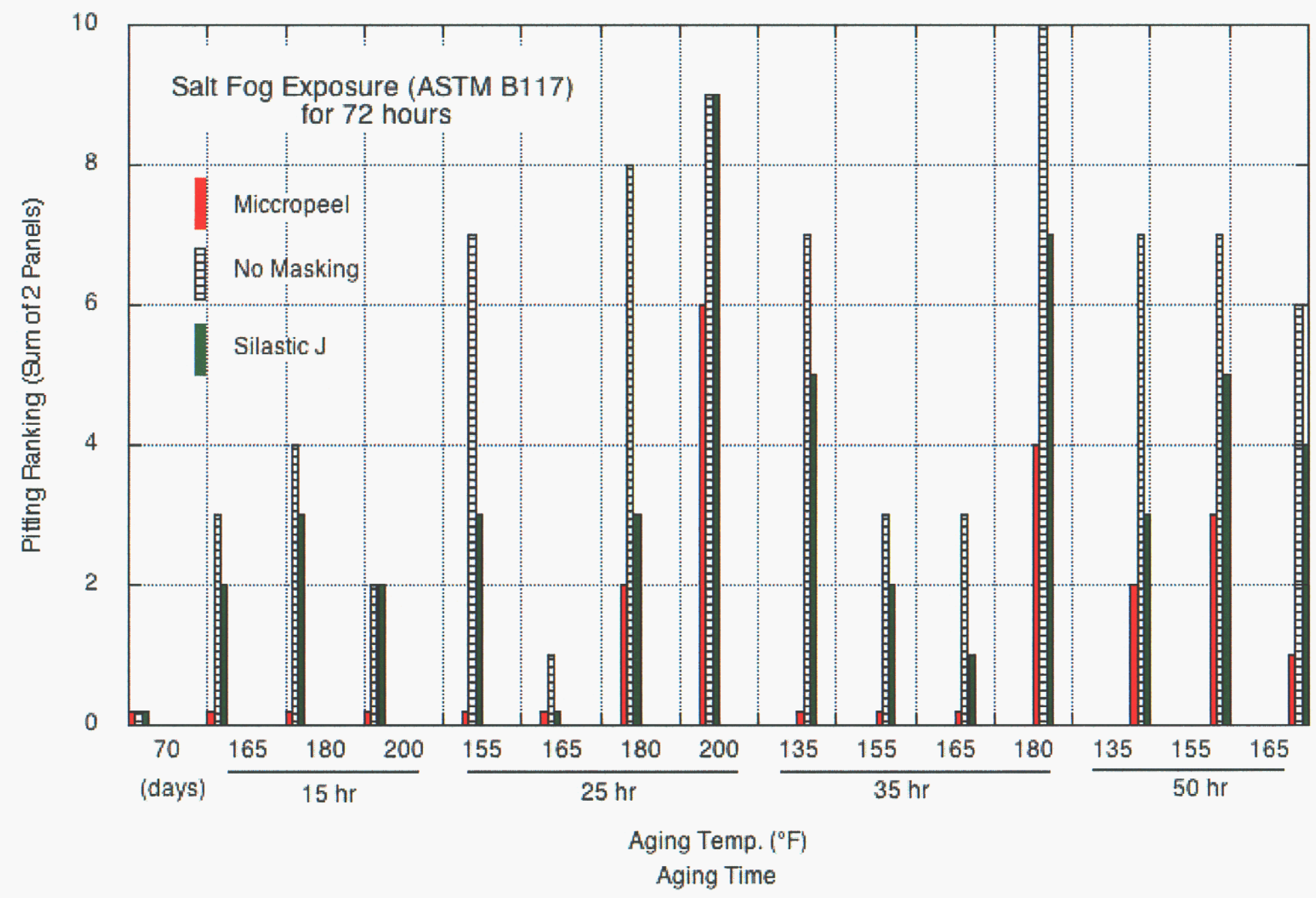

Figure 5. The effect of removable masking materials on thermal aging of Alodine Grade 1 coatings on Al-7075-T73 corrosion test panels after 72 hours in a salt fog chamber. Shorter bars indicate less pitting susceptibility. 


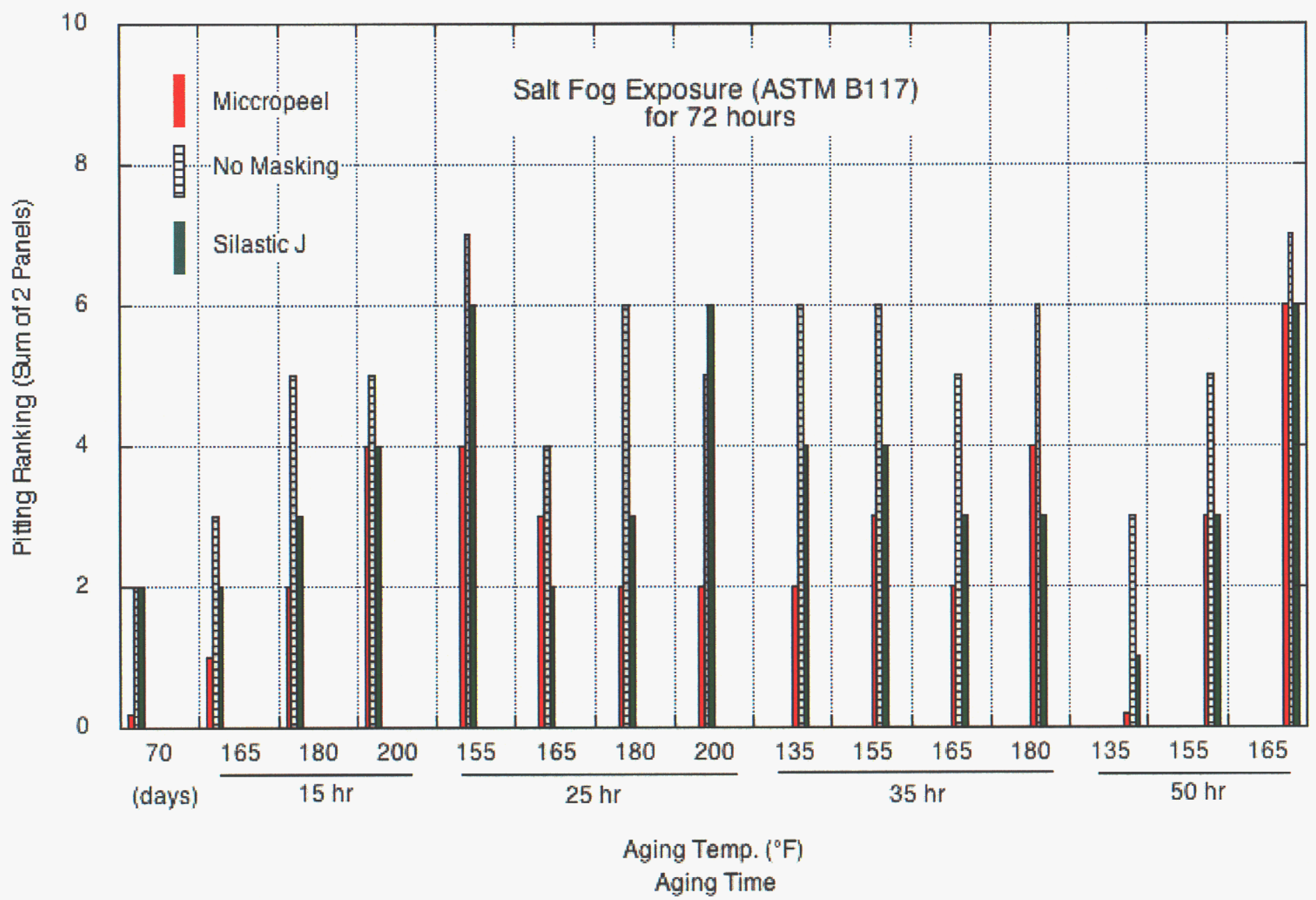

Figure 6. The effect of removable masking materials on thermal aging of Alodine Grade 1 coatings on Al-6061-T6 corrosion test panels after 72 hours in a salt fog chamber. Shorter bars indicate less pitting susceptibility. 


\section{Appendix}

\section{Pitting Data for Aluminum Alloys 7075-T73 and 6061-T6}

The experimental data for the pitting susceptibility rankings of individual panels of aluminum alloys 7075-T73 and 6061-T6 after 72 hour exposure in the salt fog chamber are collected in Table 4 . The data are organized according to the matrix of temperatures and times that the coated panels were thermally aged. The panels are identified by a code that notes the alloy type, either '7' for 7075-T73 or '6' for 6061-T6, followed by a twodigit panel number. The three-digit entry beneath the panel designations indicates the pitting ranking values for Miccropeel-coated, bare Alodine and Silastic-J-coated panel areas, respectively. For example, Al-7075-T73 panel number '7-82', aged for 15 hours at $165^{\circ} \mathrm{F}$, experienced pitting rankings of 0 in the Miccropeel-coated band, 2 in the bare Alodine band and 1 in the Silastic-J-coated band. The column labeled "No aging" refers to panels that were masked with the removable polymer coatings and then stripped but not aged. The column labeled "No masking" refers to panels that were neither masked nor aged. 
Table 4. Visually determined values of pitting susceptibility of Alodine-coated Aluminum alloys 7075-T73 and 6061-T6 after 72 hours in a salt fog chamber. Data for dehydration barrier coatings are compared following various thermal aging treatments.

\begin{tabular}{|c|c|c|c|c|c|c|c|}
\hline $\begin{array}{c}\text { Temp. } \\
\left({ }^{\circ} \mathrm{F}\right)\end{array}$ & 135 & 155 & 165 & 180 & 200 & $\begin{array}{c}\text { No } \\
\text { Aging }\end{array}$ & $\begin{array}{c}\text { No } \\
\text { Masking }\end{array}$ \\
\hline \multicolumn{8}{|l|}{$\begin{array}{l}\text { Time } \\
\text { (hours) }\end{array}$} \\
\hline \multirow[t]{8}{*}{15} & (panel) & & $7-82$ & $7-50$ & $7-76$ & $7-56$ & $7-02$ \\
\hline & (ranking) & & 021 & 021 & 011 & 000 & 1 \\
\hline & & & $7-81$ & $7-47$ & $7-41$ & $7-53$ & $7-62$ \\
\hline & & & 011 & 022 & 0011 & 000 & 0 \\
\hline & & & $6-18$ & $6-40$ & $6-45$ & $6-06$ & $6-04$ \\
\hline & & & 011 & 132 & 122 & 011 & 1 \\
\hline & & & $6-30$ & $6-48$ & $6-35$ & $6-34$ & $6-42$ \\
\hline & & & 121 & 121 & 332 & 011 & 1 \\
\hline \multirow[t]{8}{*}{25} & & $7-63$ & $7-77$ & $7-52$ & $7-57$ & & \\
\hline & & 042 & 010 & 141 & 345 & & \\
\hline & & $7-58$ & $7-60$ & $7-55$ & $7-48$ & & \\
\hline & & 021 & 000 & 142 & 354 & & \\
\hline & & $6-19$ & $6-65$ & $6-09$ & $6-36$ & & \\
\hline & & 233 & 111 & 132 & 133 & & \\
\hline & & $6-16$ & $6-31$ & $6-10$ & $6-07$ & & \\
\hline & & 243 & 231 & 131 & 123 & & \\
\hline \multirow[t]{8}{*}{34} & $7-42$ & $7-83$ & $7-49$ & $7-44$ & & & \\
\hline & 054 & 0011 & 010 & 354 & & & \\
\hline & $7-80$ & $7-69$ & $7-40$ & 743 & & & \\
\hline & 021 & 021 & 021 & 153 & & & \\
\hline & $6-55$ & $6-32$ & $6-24$ & $6-37$ & & & \\
\hline & 132 & 132 & 132 & 122 & & & \\
\hline & $6-67$ & $6-20$ & $6-66$ & $6-44$ & & & \\
\hline & 132 & 232 & 121 & 341 & & & \\
\hline \multirow[t]{8}{*}{50} & $7-61$ & $7-67$ & $7-51$ & & & & \\
\hline & 132 & 143 & 032 & & & & \\
\hline & $7-66$ & $7-79$ & $7-46$ & & & & \\
\hline & 141 & 232 & 132 & & & & \\
\hline & $6-75$ & $6-56$ & $6-62$ & & & & \\
\hline & 021 & 232 & 443 & & & & \\
\hline & $6-74$ & $6-53$ & $6-46$ & & & & \\
\hline & 010 & 121 & 233 & & & & \\
\hline
\end{tabular}




\title{
Distribution
}

\author{
3 MS $9014 \quad$ B. R. Wagstaff, 8248 \\ 1 MS $9014 \quad$ J. O. Harrison, 8241 \\ 1 MS 9014 A. H. Leung, 8241 \\ 1 MS $9014 \quad$ D. A. Neustel, 8241 \\ 3 MS $9403 \quad$ R. W. Bradshaw, 8778 \\ 1 MS 9403 T. J. Shepodd, 8778 \\ 3 MS $9403 \quad$ L. L. Whinnery, 8778
}

2 MS 9018 Central Technical Files, 8944

2 MS 0899 Technical Library, 4536 